\title{
Capacity of Broccoli to Induce a Mammalian Chemoprotective Enzyme Varies among Inbred Lines
}

\author{
Mark W. Farnham ${ }^{1}$ \\ U.S. Department of Agriculture, Agricultural Research Service, U.S. Vegetable Laboratory, 2875 Savannah \\ Hwy., Charleston, SC 29414 \\ Katherine K. Stephenson ${ }^{2}$ and Jed W. Fahey ${ }^{3}$ \\ Brassica Chemoprotection Laboratory, Johns Hopkins University, School of Medicine, Department of \\ Pharmacology and Molecular Sciences, Baltimore, MD 21205-2185
}

ADDITIONAL INDEX wORDS. doubled haploids, glucoraphanin, sulforaphane, nutrition, glucosinolates, isothiocyanates, Brassica
oleracea, Italica Group

\begin{abstract}
Broccoli (Brassica oleracea L., Italica Group) has been recognized as a source of glucosinolates and their isothiocyanate metabolites that may be chemoprotective against human cancer. A predominant glucosinolate of broccoli is glucoraphanin and its cognate isothiocyanate is sulforaphane. Sulforaphane has been shown to be a potent inducer of mammalian detoxication (Phase 2) enzyme activity and to inhibit chemical-induced tumorigenesis in animal models. Little is known about phenotypic variation in broccoli germplasm for Phase 2 enzyme (e.g., quinone reductase) induction potential. Thus, this study was undertaken to evaluate: 1) quinone reductase induction potential (QRIP) diversity among a population of broccoli inbreds; 2) QRIP levels in selected lines; 3) correlation of QRIP with other horticultural characteristics; and 4) QRIP expression in a sample of synthesized hybrids. In 1996, 71 inbreds and five hybrid checks (all field-grown), ranged from a QRIP of nearly zero to 150,000 units/g fresh weight $(\mathrm{FW})$ (mean of 34,020 units/g FW). These values were highly correlated with methylsulphinylalkyl glucosinolate (MSAG; primarily glucoraphanin) concentrations that ranged from 0.04 to 2.94 $\mu \mathrm{mol} \cdot \mathrm{g}^{-1} \mathrm{FW}$. A select subset of lines evaluated in 1996 were reevaluated in 1997. QRIP and MSAG values in this second year were similar to and correlated with those observed in $1996(r=0.73, P<0.0001$ and $r=0.79, P<0.0001$, respectively). In addition, both QRIP and MSAG concentration were highly correlated with days from transplant to harvest. Average $F_{1}$ hybrid values for QRIP and MSAG in 1997 fell typically between their parental means, but were often closer to the mean of the low parent. Results of this study indicate that divergent QRIP expression can effectively be used to select enhanced inbred lines to use in development of value-added hybrids. Evidence is also provided that there is a significant genetic component to both QRIP and MSAG concentration, and that selection for either one may provide an effective means for developing broccoli hybrids with enhanced chemoprotective attributes. Chemical names used: 4-methylsulphinylbutyl glucosinolate (glucoraphanin) and 4-methylsulphinylbutyl isothiocyanate (sulforaphane).
\end{abstract}

A large body of epidemiological evidence points to vegetables as a dietary source of chemoprotective activity for humans (reviewed by Block et al., 1992; Steinmetz and Potter, 1996). Protective effects due to ingestion of Brassica oleracea vegetables, such as broccoli (B. oleracea, Italica Group), are drawing increased scientific attention and have been the subject of recent reviews (Beecher et al., 1994; Verhoeven et al, 1997). Reevaluation of data from multiple studies by meta-analysis has shown a significant reduction in the odds ratio of colon and rectal cancers associated with the consumption of B. oleracea vegetables (Kohlmeier and Su, 1997). Most recently, Michaud et al. (1999) reported results from a large cohort study in which there was a significant correlation between cruciferous vegetable consumption and reduction in bladder cancer incidence.

Brassica oleracea vegetables, like all cruciferous species, are

Received for publication 19 Aug. 1999. Accepted for publication 16 Mar. 2000. We acknowledge J. Troyer for providing analysis confirming identification of GI, A. Sylvester for assistance in plant extraction, and E. Gomperts for management and harvest of field plots. Funding was provided in part by the National Cancer Institute, Department of Health and Human Services (P01 CA 44530), the Lewis and Dorothy Cullman Foundation, and Charles B. Benenson and other friends of the Brassica Chemoprotection Laboratory. Use of a company name or product by the USDA does not imply approval or recommendation of the product to the exclusion of others that also may be suitable. The cost of publishing this paper was defrayed in part by the payment of page charges. Under postal regulations, this paper therefore must be hereby marked advertisement solely to indicate this fact. ${ }^{1}$ Research geneticist.

${ }^{2}$ Research assistant.

${ }^{3}$ Faculty research associate. well known as sources of glucosinolates: $\beta$-thioglucoside $N$ hydroxysulfates, with an aglycone (or R-group) that is an alkyl, alkenyl, thioalkyl, thioalkenyl, aryl, arylalkyl or indolyl moiety (Fig. 1) (Rosa et al., 1997). Glucosinolates are hydrolyzed to their cognate isothiocyanates by myrosinase which is present in both plant cells and in human gut microflora (Shapiro et al., 1998). More than 20 isothiocyanates have been shown to inhibit the formation of tumors initiated by a variety of chemical carcinogens in several organ systems (Hecht, 1995; Zhang and Talalay, 1994). Of special interest is sulforaphane, the cognate isothiocyanate of glucoraphanin (4-methylsulfinyl-butyl glucosinolate; GR), that is a potent inducer of mammalian detoxication (Phase 2) enzyme activity. Sulforaphane also protects against tumorigenesis in a rodent mammary tumor model (Fahey et al., 1997; Zhang et al., 1994; Zhang et al., 1992). Broccoli florets and young seedlings or sprouts are the primary dietary sources of sulforaphane and GR (Fahey et al., 1997; Zhang et al., 1992). There is a substantial body of evidence that Phase 2 enzymes [e.g., glutathione transferase, $\mathrm{NAD}(\mathrm{P}) \mathrm{H}$ :quinone reductase (QR), epoxide hydrolase, heme oxygenase, UDPglucuronosyl transferase] play important roles in the detoxication of electrophiles and that their induction suppresses carcinogenesis and mutagenesis (Benson et al., 1978, 1980; Kensler, 1997; Prestera et al., 1995; Talalay, 1992).

GR is by far the most abundant thioalkyl glucosinolate present in harvested heads of cultivated broccoli (Fig. 1); however, three other thioalkyl glucosinolates, glucoiberin (GI; 3-methylsulfinylpropyl glucosinolate), glucoerucin (GE; 4-methylthiobutyl 
glucosinolate), and glucoalyssin (GA; 5-methylsulfinylpentyl glucosinolate) have also been identified in broccoli heads. The concentrations of GI range from $0 \%$ to $10 \%$ that of GR, while those for GE and GA are much less than 5\% that of GR (Carlson et al., 1987; Kushad et al., 1999; Shelp et al., 1993). Iberin, erucin, and alyssin (cognate isothiocyanates of GI, GE, and GA, respectively) have only $\approx 20 \%, 10 \%$, and $10 \%$, respectively, of the Phase 2 enzyme induction potential of sulforaphane (Prestera et al., 1993; Zhang et al., 1992), and thus account typically for no more than $\approx 2 \%$ of the total glucosinolate-derived Phase 2 induction potency of broccoli. Other glucosinolates present in broccoli heads, such as glucobrassicin (indole-3-ylmethyl glucosinolate), neoglucobrassicin (1-methoxyindole-3-ylmethyl glucosinolate), and 4-hydroxyglucobrassicin (Fig. 1), have no significant Phase 2 inducer potential (Fahey et al., 1997; Fahey et al., 1998).

There is considerable interest in understanding how to control GR levels in broccoli in order to create added value in this vegetable for its development as a functional food, and to enhance its utility in dietary chemoprotection strategies (Giamoustaris and Mithen, 1996; Kushad et al., 1999; Shapiro et al., 1998). Faulkner et al. (1998) have suggested that genetic factors which induce high levels of the methylsulphinylalkyl glucosinolates (MSAG) in wild relatives of B. oleracea could be transferred to cultivated broccoli. They have shown that hybrids formed by crossing broccoli inbreds and wild relatives express much higher Phase 2 enzyme induction potential than the broccoli inbreds themselves. Although this approach may ultimately yield a commercially viable cultivar, broccoli lines resulting from the broccoli $\mathrm{X}$ wild relative crosses will likely require numerous generations of selection to improve the horticultural phenotype of resulting lines.

The object of the current breeding study was to better characterize Phase 2 enzyme induction potential of relatively elite and diverse broccoli inbred (doubled-haploid) lines that have horticultural characteristics which approach market quality. If genetic variation exists within an elite broccoli germplasm pool and this variation can be exploited, then cultivar development should proceed rapidly. Kushad et al. (1999) examined a set of $24 \mathrm{~F}_{1}$ hybrid and open-pollinated cultivars and 26 inbred lines of broccoli in a single environment and observed a range of GR at 1.5 to $21.7 \mu \mathrm{mol} \cdot \mathrm{g}^{-1}$ dry head weight for cultivars and a range of GR at 0.8 to $13.8 \mu \mathrm{mol} \cdot \mathrm{g}^{-1}$ dry head weight for inbreds. Those authors concluded that significant variation for GR concentration was present in the germplasm examined. However, they did not examine Phase 2 enzyme induction potential of these lines.

In the present study, a larger and more diverse pool of inbred broccoli lines was examined. Specific objectives were to evaluate 1) quinone reductase induction potential (QRIP) diversity among head samples from a population of broccoli lines in a single environment; 2) QRIP of lines selected based on 1996 induction potentials when measured subsequently in 1997; 3) QRIP correlation with head MSAG concentration, head weight, and number of days from transplant to harvest among inbreds; and 4) QRIP in a sample of hybrids made by crossing specific inbreds.

\section{Materials and Methods}

Plant material. Plant materials evaluated in this study included 73 doubled haploid or inbred lines developed at the U.S. Vegetable Laboratory, Charleston, S.C. These inbreds were a subset of lines developed from the commercial hybrid broccoli cultivars Arcadia, Everest, Eureka, Futura, Green Valiant, High
Sierra, Marathon, Packman, Southern Comet, Sultan, Symphony, and Viking using standard anther culture techniques (Farnham, 1998) or conventional selfing. These lines were designated as USVL001 through USVL070, USVL073, USVL075, and USVL076. All inbred seed were produced onsite at the U.S. Vegetable Laboratory. The 73 inbreds were selected from a large pool of inbred lines originating in the U.S. Vegetable Laboratory breeding program and they represent a diverse phenotypic and genotypic sample of relatively elite broccoli.

Commercial $F_{1}$ hybrid cultivars were also grown and evaluated to serve as reference checks in these studies. In addition, several $F_{1}$ hybrid crosses were generated in a greenhouse during Winter 1996-97 using some of the inbreds described above. Four of the resulting hybrids were evaluated in 1997. All crosses were made following emasculation of females to insure that no selfed seed were produced from the respective crosses.

Plant culture. In 1996, 71 inbreds and five hybrid cultivars including Everest, High Sierra, Marathon, Sultan, and Viking were seeded to a commercial potting mix (Metromix 360; Grace Sierra, Milpitas, Calif.) in trays in a greenhouse during the first week of August, and transplanted to the field 7 Sept. All entries were grown in individual plots consisting of a single row of eight to ten plants, and randomly incorporated into a single block of a<smiles>[R][CH]CS(C)=O</smiles>

\section{Glucoraphanin}

(4-methylsulfinylbutyl glucosinolate)<smiles>[R][Hg]CCS(C)=O</smiles>

\section{Glucoiberin}

(3-methylsulfinylpropyl glucosinolate)<smiles>[R][Hg]CCS(C)=O</smiles>

Glucoalyssin

(5-methylsulfinylpentyl glucosinolate)

$\mathrm{CH}_{3}-\mathrm{S}-\left(\mathrm{CH}_{2}\right)_{4}-\mathrm{R}$

Glucoerucin

(4-methylthiobutyl glucosinolate)

\section{$\mathrm{CH}_{2}=\mathrm{CH}-\mathrm{CH}_{2}-\mathrm{R}$}

Sinigrin

(allyl glucosinolate)

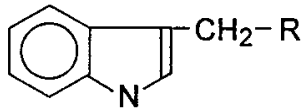

\section{Glucobrassicin} (indole-3-ylmethyl glucosinolate)

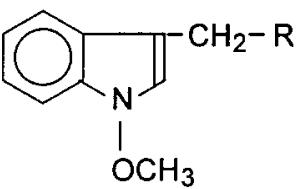
(1-methoxyindole-3-ylmethyl glucosinolate)
Neoglucobrassicin

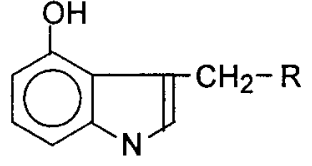

4-Hydroxyglucobrassicin (4-hydroxyindole-3-ylmethy! glucosinolate)

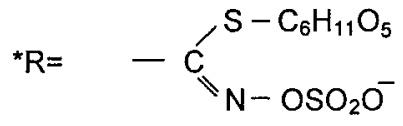

Fig. 1. Glucosinolates that are found in broccoli. 
field nursery. Additionally, a subset of eight inbred entries and the five hybrid cultivars were transplanted simultaneously to eight to ten plant plots in a second block adjacent to the first. Spacing between rows was $102 \mathrm{~cm}$, and spacing between plants within a row was $15 \mathrm{~cm}$ throughout the nursery. The subset of entries with two replicate samples (one from the first and the other from the second block) were treated as a separate experiment (i.e., randomized complete block with two replications) within the 1996 field nursery for statistical analysis. All cultural practices (e.g., cultivation, fertilization, and irrigation) for the 1996 trial were standard for local conditions (Cook and Ezell, 1983). The soil type at the Charleston site is a Yonges loamy sand (fine loamy mixed, thermic Albaqualfs).

In 1997, 21 of the 71 inbreds grown in 1996, two additional inbreds, the five hybrid cultivars Everest, High Sierra, Marathon, Viking, and Futura, and four $\mathrm{F}_{1}$ hybrids produced in Charleston were seeded to the greenhouse 5 Aug. Inbreds grown in 1997 were selected based on their 1996 QRIP values and on their pedigree. These individuals were selected to represent a range of QRIP while maintaining phenotypic and genotypic variation in the second sampling year. The $\mathrm{F}_{1}$ hybrids produced in Charleston were crosses of inbreds that expressed divergent levels of QRIP in 1996. All entries were transplanted to field plots on 4 Sept. The study was designed as a randomized complete block with each of the three blocks containing plots of all entries (6 to 10 plants, depending on available seed supplies). Spacing and cultural practices were the same as in 1996.

Head harvest, SAMPling, and eXtraction. As plots approached maturity in both years, trials were checked every 2 to 3 $\mathrm{d}$ to identify plants ready for harvest, until studies were completed. In all trials and with all entries, heads were harvested when head diameter reached 10 to $12 \mathrm{~cm}$. Two heads per plot were sampled at random, and subtending stalks were cut to a $15-\mathrm{cm}$ length. Sample date was recorded for calculation of the mean number of days from transplant to harvest (DTH). Heads were placed immediately on ice in a cooler and within 30 min of field harvest, fresh weights were recorded, ca. half of the florets were cut from the stem, placed in an individual sealable freezer bag, and frozen at $-80^{\circ} \mathrm{C}$. At the end of each growing season, samples were transported to Baltimore, Md., on dry ice for storage at -80 ${ }^{\circ} \mathrm{C}$ before analysis. In processing samples for analysis, frozen florets $(\approx 30$ to $40 \mathrm{~g}$ ) were removed from storage, weighed, and extracted as described by Fahey et al. (1997). Extracts were then stored at $-20{ }^{\circ} \mathrm{C}$ until needed for bioassay of QRIP and for direct quantitation of glucosinolates by paired ion chromatography.

BIOASSAY OF QUINONE REDUCTASE INDUCTION POTENTIAL (QRIP). Bioassay of QRIP was performed using Hepa 1c1c7 cells as described originally by Prochaska et al. (1992) and modified by Fahey et al. (1997). Excess myrosinase, [0.0003 units/mL of cell culture medium; purified according to the methods of Shikita et al. (1999)], was added at the time of dosing along with $500 \mu \mathrm{M}$ ascorbate, in order to achieve complete hydrolysis of glucosinolates to their cognate isothiocyanates. Conversion of glucosinolates in broccoli extracts, to their cognate isothiocyanates, is essentially quantitative by this procedure (Fahey, unpublished results). One unit of inducer activity is the amount that doubles the QR activity in a microtiter well containing $150 \mu \mathrm{L}$ of medium. Hence, a compound with a $\mathrm{CD}$ (the concentration of a compound required to double the QR specific activity in Hepa 1c1c7 murine hepatoma cells) of $1.0 \mu \mathrm{M}$ has 6,667 units of inducer activity/ $\mu \mathrm{mol}$. We expressed the inducer potency of plant extracts as units per gram fresh weight $(\mathrm{FW})$.
Paired-ion Chromatography of glucosinolates. Plant extracts were chromatographed isocratically in 1 acetonitrile : 1 water $(\mathrm{v} / \mathrm{v})$ containing $5 \mathrm{~mm}$ tetradecylammonium bromide (TDAB) at a flow rate of $3 \mathrm{~mL} \cdot \mathrm{min}^{-1}$, on a reverse-phase column (Whatman Partisil 10 ODS-2, $250 \times 4 \mathrm{~mm}$; Whatman, Inc., Clifton, N.J.) using a Waters (Waters Corp., Milford, Mass.) high-performance liquid chromatography (HPLC) system equipped with a photodiode array detector (Prestera et al., 1996). Sinigrin (allyl glucosinolate) was used as a standard. When compared to equimolar concentrations of sinigrin, the relative integrated absorbance areas for alkyl glucosinolates (GR, GI, and GE), glucobrassicin, and neoglucobrassicin at $235 \mathrm{~nm}$ were 1.00-, 1.22-, and 2.70-fold greater. The use of TDAB, an otherwise ideal paired-ion solvent system, does not permit resolution of GR from GI, which has been identified as a minor component in most broccoli samples. In this study, a subset of representative germplasm from both trial years was subjected to chromatography using $5 \mathrm{~mm}$ tetramethylammonium bromide (TMAB) in water at a flow rate of $2 \mathrm{~mL} \cdot \mathrm{min}^{-1}$ on the same column and HPLC system described in the preceding paragraph. Glucosinolate identities were confirmed using a complimentary, normal-phase HPLC method (J. Troyer, personal communication). GI was not detected in over half of these samples and on average, accounted for $<4 \%$ of the GR/GI peak obtained using TDAB as a paired ion. Based on these observations, although we report these data as MSAG (GR+GI) concentrations, GI is considered a minor component in all lines examined herein, while GR comprises well over $90 \%$ of the MSAG content.

DATA ANALYSIS. Analyses of variance (ANOVA) of the subset of replicated samples from 1996 and the entire 1997 trial were performed using Proc GLM of SAS (release 6.12, SAS Inst., Inc., Cary, N.C.). Entry means were compared using Fisher's protected LSD. Pearson correlation coefficients were calculated for all pairs of QRIP, MSAG concentration, head weight, and DTH. Reported values are followed by the SE where appropriate.

\section{Results}

The QRIP of all broccoli heads harvested in 1996 ranged from essentially zero to 150,000 units/g FW and the overall mean was 34,000 $\pm 3,000$ units/g FW (Fig. 2A). The 1996 range for MSAG concentration was 0.04 to $2.94 \mu \mathrm{mol} \cdot \mathrm{g}^{-1} \mathrm{FW}$ (mean of $0.88 \pm 0.07$ $\mu \mathrm{mol} \cdot \mathrm{g}^{-1} \mathrm{FW}$ ) for this same set of broccoli entries (Fig. 2B).

A subset of entries for which replicate measurements of QRIP were obtained had a range of QRIP from 5,500 to 69,100 units/g FW (Fig. 3), with significant differences among entries $\left(\mathrm{LSD}_{0.05}\right.$ of 14,600 units/g FW). As with QRIP, there were significant differences in MSAG concentration for this subset (range 0.15 to 2.05 $\mu \mathrm{mol} \cdot \mathrm{g}^{-1} \mathrm{FW}, \mathrm{LSD}_{0.05}$ of $\left.0.29 \mu \mathrm{mol} \cdot \mathrm{g}^{-1} \mathrm{FW}\right)$.

There was a highly significant correlation $(r=0.93, P<$ 0.0001 ) between QRIP and MSAG of entries assayed in 1996. In addition, there was a significant positive correlation between DTH and QRIP $(r=0.78, P<0.0001)$ and between DTH and MSAG $(r=0.74, P<0.0001)$ of entries.

The set of entries from 1996 that were chosen for retest in 1997, had a 1996 range for QRIP of 1,000 to 142,000 units/g FW and a mean of $42,800 \pm 6,100$ units/g FW. In addition, this same set of entries had a $1996 \mathrm{MSAG}$ range of 0.15 to $2.72 \mu \mathrm{mol} \cdot \mathrm{g}^{-1} \mathrm{FW}$ and mean of $1.10 \pm 0.13 \mu \mathrm{mol} \cdot \mathrm{g}^{-1} \mathrm{FW}$. These 1996 ranges and means of this selected subset of entries are similar to the ranges and means for the entire sample of entries grown in 1996.

The QRIP of entries grown in 1997 correlated with QRIP of 

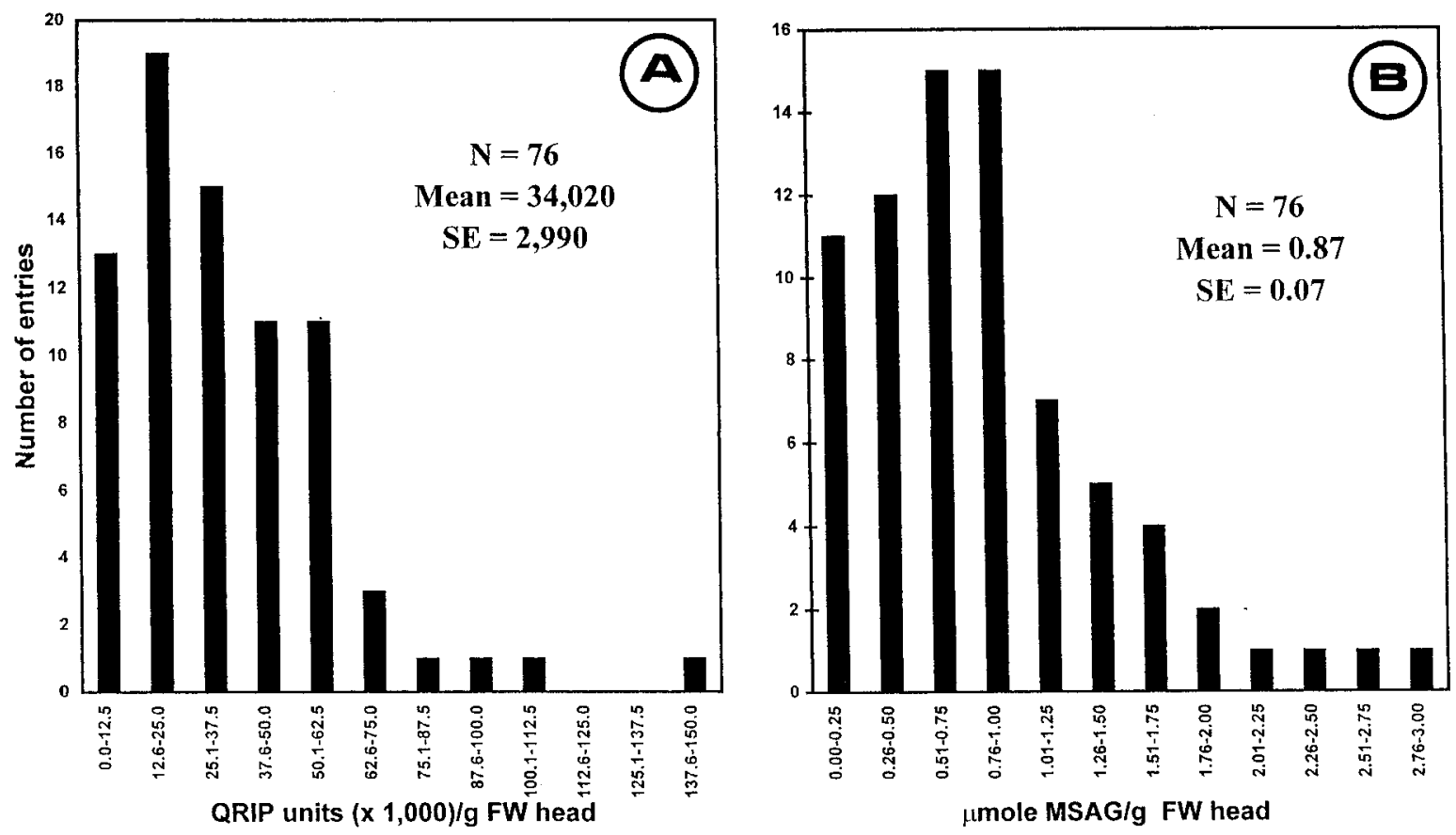

Fig. 2. Distribution of (A) quinone reductase induction potential (QRIP) and (B) methylsulphinylalkyl glucosinolate (MSAG) concentration among broccoli entries grown in 1996.

those same entries grown in 1996 ( $r=0.73, P<0.0001$; Fig. 4A). The range of QRIP values was 15,800 to 150,200 units/g FW in 1997 and the mean QRIP for all entries was 63,200 units/g FW. ANOVA indicated highly significant differences among the entries in this second year.

As with QRIP, MSAG means for entries grown in 1997 also correlated with values for the same entries grown in 1996 ( $r=$ $0.79, P<0.0001$; Fig. 4B). The range $\left(0.24\right.$ to $\left.2.99 \mu \mathrm{mol} \cdot \mathrm{g}^{-1} \mathrm{FW}\right)$ for MSAG concentration in 1997 was nearly identical to that for entries grown the previous year. The overall MSAG mean for 1997 was $1.33 \mu \mathrm{mol} \cdot \mathrm{g}^{-1} \mathrm{FW}$, and ANOVA indicated significant differences among entries.

As observed in the 1996 trial, there was a significant and positive correlation in 1997 between entry means for QRIP and MSAG concentration $(r=0.90, P<0.0001)$. In addition, DTH among entries was significantly and positively correlated with QRIP $(r=0.79, P<0.0001)$ and MSAG concentration $(r=0.78$, $P<0.0001)$. On the contrary, no significant correlations were observed between head weight and the other measured characters.

Of four hybrid crosses evaluated in 1997, only two (1 and 2) were actually made using parents with significantly different QRIP means (Table 1). The $F_{1}$ mean for Cross 1 was intermediate between that of the high and low parents, and the $F_{1}$ mean for Cross 2 was lower than that of the low parent. For cross 3 , the $F_{1}$ mean was again intermediate between the high and low parents. Cross 4 had parental and $F_{1}$ QRIP means that were all similar.

All four crosses evaluated involved combinations of parents with significantly different MSAG means (Table 1). In all cases, the $F_{1}$ mean was intermediate between means of the high and low parents. In two crosses ( 1 and 4 ), the $F_{1}$ was closer to the high parent while for the other two ( 2 and 3 ), the $F_{1}$ was closer to the low parent.

Similar to observations for MSAG concentration, all crosses involved combinations of inbred parents with significantly different mean DTH (Table 1). For two crosses (1 and 3), the DTH mean of the $F_{1}$ fell in between that of high and low parents but closer to the low parent, while in the other two crosses ( 2 and 4 ), the $F_{1}$ mean was lower than the mean of the low parent.

\section{Discussion}

This is the first report in which Phase 2 detoxication enzyme (quinone reductase) induction potential of broccoli heads has been examined using a relatively large and diverse pool of inbred (primarily doubled-haploid) lines. This work is consistent with

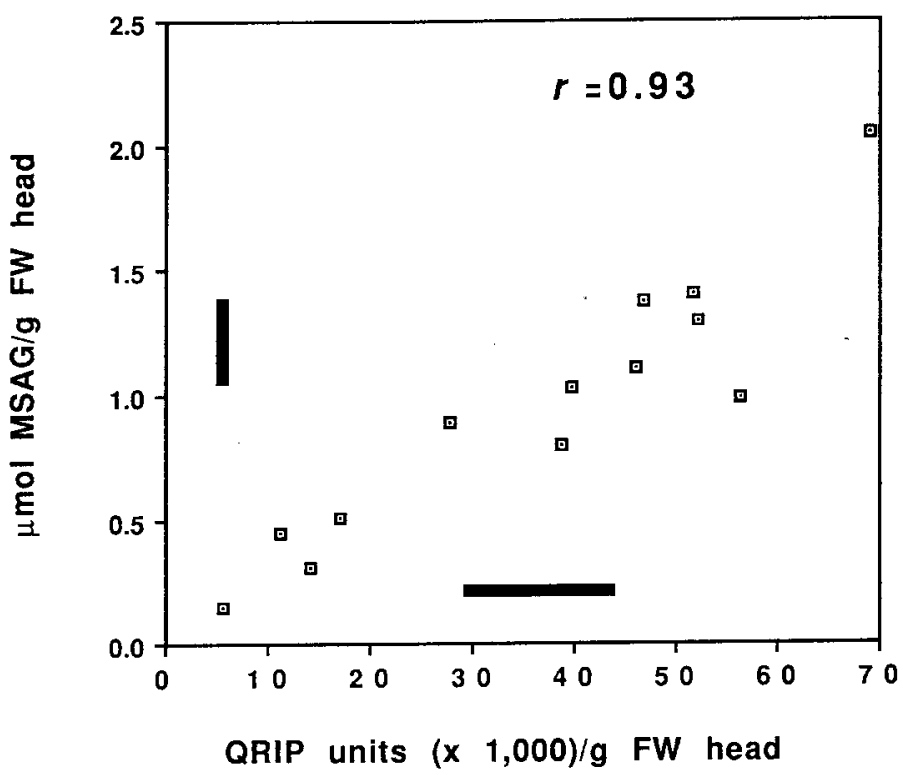

Fig. 3. Mean quinone reductase induction potential (QRIP; $x$-axis) and methylsulphinylalkyl glucosinolate (MSAG) concentration (y-axis) of entries replicated within the 1996 field environment. Horizontal and vertical bars on graph represent the $\mathrm{LSD}_{0.05}$ for differentiating entry means for QRIP and MSAG concentration, respectively. 
the hypothesis that the primary broccoli inducer of detoxication enzymes is glucoraphanin, concentrations of which were elevated concomitantly with QRIP in inbreds and hybrids created from them. Faulkner et al. (1998) also found that MSAG (primarily glucoraphanin) and QRIP were interrelated in broccoli; however, results described herein, are based on a much larger pool of broccoli entries, a more elite pool of germplasm, and samples harvested from field-grown plants. Whereas other recent studies on the phytochemical attributes of broccoli and other $B$. oleracea crops focus primarily on glucosinolate content (i.e., Kushad et al., 1999), our primary focus is the potential for these vegetables to induce Phase 2 enzyme activity in a versatile in vitro mammalian cell bioassay system (Talalay et al., 1995). Whereas Faulkner et al. (1998) have suggested that increased Phase 2 induction potential can be transferred from related wild species to broccoli, results herein suggest that diversity already extant within elite broccoli germplasm might be exploited in a program
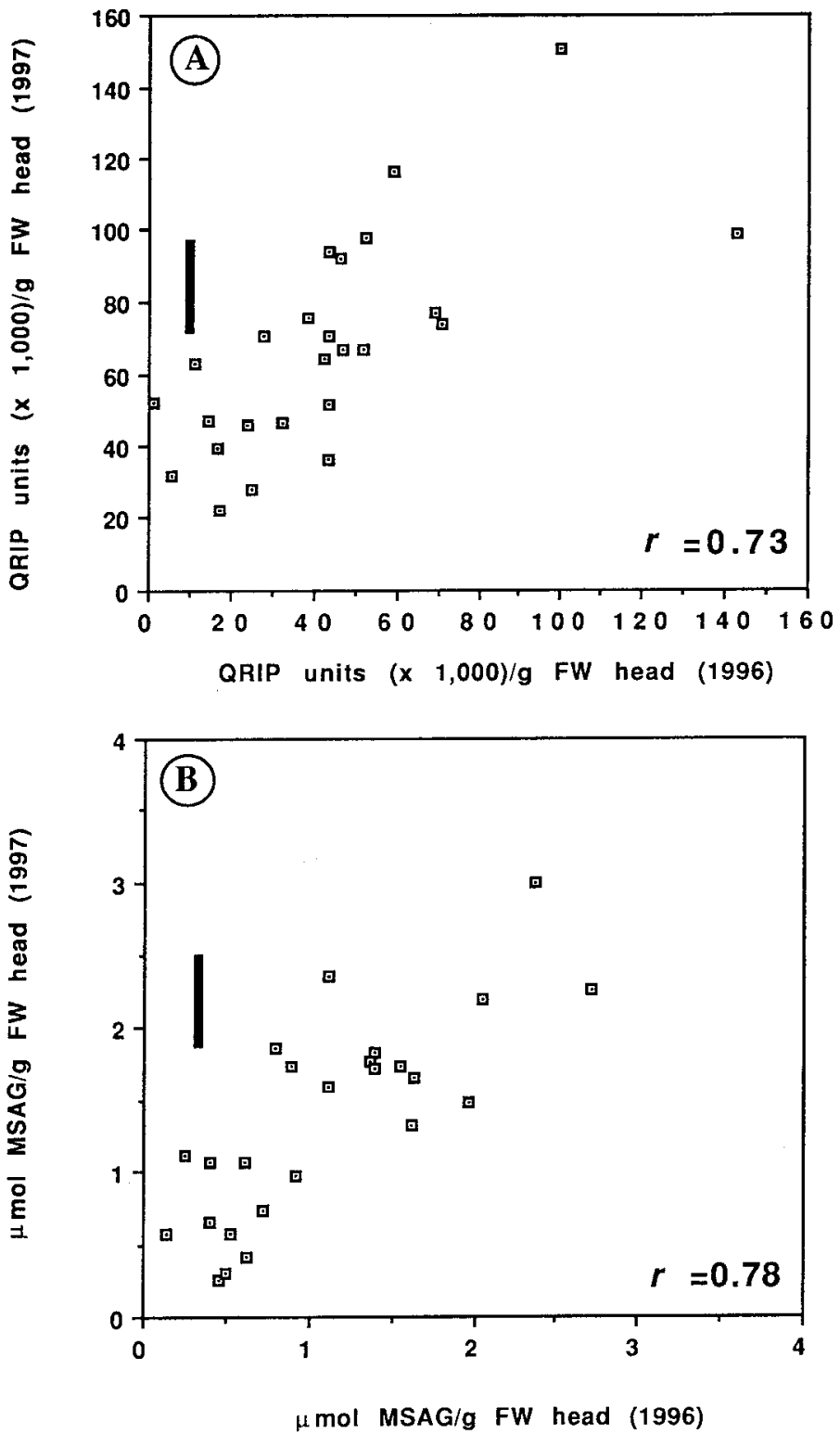

Fig. 4. (A) Mean quinone reductase induction potential (QRIP) and (B) methylsulphinylalkyl glucosinolate (MSAG) concentration of entries grown in 1997 (y-axis) as a function of entry phenotype in 1996 (x-axis). Vertical bar in each graph represents the $\mathrm{LSD}_{0.05}$ for differentiating entry means in 1997. of hybridization and rapid development of enhanced doubledhaploid lines.

In an initial screen of broccoli inbreds in 1996, a wide range of QRIP was observed (0 to 150,000 units/g FW), based on single plant samples. A mean of 34,000 units/g FW for this 1996 sampling of inbreds was virtually identical to that reported by Fahey et al. (1997) for a random sample of broccoli heads obtained from supermarkets. The magnitude of the SD for the sampled population and of the SE for QRIP indicates that differences among tested entries in 1996 were likely due in part to genotypic effects. The importance of entry (and presumably genotype) in 1996 was supported by detection of significant differences for QRIP among a subset of replicated entries.

Line selection for QRIP based on individual samples in an initial test effectively identified lines with differing phenotypic expression of QRIP in a subsequent environment. This is best illustrated by comparing means of the five lines selected for highest QRIP (88,400 units/g FW in 1996 and 103,100 units/g $\mathrm{FW}$ when regrown in 1997) to means of the five lines selected for lowest potential (9,900 units/g FW in 1996, and 33,700 units/g FW when regrown in 1997). The 1996 QRIP mean of all entries was 34,000 units/g FW and the 1997 mean was 63,200 units/g FW. Higher QRIP values for entries in 1997 compared to 1996, are probably due in part to environmental factors. These differences between years are also partially explained by the fact that individuals selected to be grown in 1997 had QRIP levels in 1996 that were evenly distributed along the range of values for the trait; whereas, the 1996 sample was weighted with entries that had moderate to low levels of induction potential. However, it is clear that differential expression between high and low QRIP inbreds was consistent in both years. MSAG concentration differentials between the above-described five high versus five low lines were also concordant: $2.13,0.35,2.13$, and $0.58 \mu \mathrm{mol} \cdot \mathrm{g}^{-1} \mathrm{FW}$ for the high and low lines of 1996 and 1997, respectively. The QRIP bioassay thus identifies lines divergent for MSAG concentration.

Few studies have measured the genetic versus environmental contribution to MSAG content of broccoli. Carlson et al. (1987) and Kushad et al. (1999) found very low levels of GI compared to GR, and significant differences among broccoli entries for GR concentration, but looked only at a single environment. Shelp et al. (1993) grew two cultivars of broccoli in several environments, reported only GR levels, and found a significant effect of genotype and environment on the concentration of this glucosinolate. However, those authors utilized two relatively early maturing cultivars, Commander and Baccus, and the magnitude of differences between the two cultivars was small compared to the ranges observed by Carlson et al. (1987), Kushad et al. (1999), and those described herein. Conclusions from the present study are based on only two autumn harvest environments, but results indicate a significant role of genotype in expression of GR levels, in broccoli heads.

It is noteworthy, that Kushad et al. (1999) evaluated inbred lines developed by one of the present authors (M.W. Farnham), citing 'VI158' as a line with about six times more GR than 'EV21 '. In our 1996 trial, line 'VI158' (USVL068) had $\approx 7$-fold higher GR than USVL003, which is a sister line of 'EV2-1'. Inbreds USVL066 and USVL069, which exhibited the highest QRIP and MSAG levels in this study are closely related to 'VI158' and are derived from 'Viking'. In addition, several inbreds, such as USVL003 and USVL013, with low QRIP and MSAG in the trials reported herein, as well as 'EV2-1', are all derived from 'Everest'. These observations provide circumstantial evidence that geno- 
Table 1. Entry means for quinone reductase induction potential (QRIP), methylsulphinyl-alkyl glucosinolate (MSAG) concentration, and number of days from transplant to harvest (DTH) for the high parent (HP) and low parent (LP), and the $\mathrm{F}_{1}$ formed by crossing the two parents for four different hybrid combinations.

\begin{tabular}{lcccr}
\hline \hline Cross & $\begin{array}{c}\text { Entry } \\
\text { type }\end{array}$ & $\begin{array}{c}\text { QRIP } \\
\left(\text { units } / \mathrm{g} \mathrm{FW}^{2}\right)\end{array}$ & $\begin{array}{c}\text { MSAG } \\
\left(\mu \mathrm{mol} \cdot \mathrm{g}^{-1} \mathrm{FW}\right)\end{array}$ & $\begin{array}{r}\text { DTH } \\
(\mathrm{d})\end{array}$ \\
\hline 1 & $\mathrm{HP}$ & 106,000 & 1.65 & 103 \\
& $\mathrm{LP}$ & 27,700 & 0.42 & 49 \\
& $\mathrm{~F}_{1}$ & 45,800 & 1.25 & 62 \\
2 & $\mathrm{HP}$ & 97,500 & 1.83 & 92 \\
& $\mathrm{LP}$ & 63,900 & 1.07 & 86 \\
& $\mathrm{~F}$ & 42,100 & 1.17 & 76 \\
3 & $\mathrm{HP}$ & 45,200 & 1.01 & 85 \\
& $\mathrm{LP}$ & 27,700 & 0.42 & 49 \\
& $\mathrm{~F}$ & 36,400 & 0.69 & 59 \\
4 & $\mathrm{HP}$ & 51,700 & 1.32 & 87 \\
& $\mathrm{LP}$ & 46,900 & 0.66 & 69 \\
& $\mathrm{~F}$ & 57,600 & 1.11 & 65 \\
& & 24,700 & 0.60 & 6 \\
\hline LSD $_{0.05}$ & & & &
\end{tabular}

${ }^{\mathrm{z}} \mathrm{FW}=$ fresh weight.

type plays a significant role in the expression of GR content, and thus, QRIP in broccoli.

Giamoustaris and Mithen (1996) provided evidence for a model in Brassica L. whereby two primary loci control the balance of alkyl glucosinolate forms in this genus. Their model suggests that the Gsl-elong locus controls elongation of the glucosinolate amino acid-derived side chain, and that the Gsl-alk locus controls formation of alkenyl glucosinolates from alkyl glucosinolates. They hypothesize a functional Gsl-elong locus and a null allele at the Gsl-alk locus in broccoli that would result in accumulation of GR. The evidence for this model is very strong, but it does not explain entirely the wide variation in broccoli head GR levels that have been observed by others and are described herein. It is likely that genes other than those hypothesized, also influence MSAG levels in broccoli.

Nearly all broccoli consumed in the United States is harvested from hybrid production fields. Although it is important to evaluate Phase 2 induction potential and GR content of inbreds, attention must be focused on expression of these traits in hybrid combinations. Thus, in the current study, a limited sample of hybrids formed from USVL inbreds were examined in order to identify possible trends. In most cases, $\mathrm{F}_{1}$ hybrid means for QRIP and MSAG concentration were intermediate between the means of the two parents but closer to the mean of the low parent. A similar trend was observed for DTH, although with two crosses, $F_{1}$ hybrid means were actually lower than means of the low parents. These observations for DTH reported herein are consistent with results of others (Borchers, 1968; Hulbert and Orton, 1984) who have concluded that days to maturity in broccoli is primarily a consequence of additive gene action with some contribution of dominance to variance that tends in the direction of earliness. Similar, although less consistent observations for the correlation of QRIP and MSAG with DTH may also point to a close relationship between maturity and the level of GR in broccoli heads, which in turn controls QRIP of this vegetable. Future studies must examine a larger sample of $F_{1}$ hybrids made by crossing inbreds of known QRIP and MSAG level to determine if trends for these characters observed herein are consistent in a larger population of hybrid crosses and whether gene action similar to that for DTH might control QRIP and MSAG as well.

The bioassay for QRIP was used initially to identify chemoprotective compounds, both natural and synthetic (Prochaska et al., 1992), and has been used successfully to identify Phase 2 enzyme inducing constituents in broccoli (sulforaphane), red wine (resveratrol), broccoli sprouts (GR), and tomatillos (withantholides), (Fahey et al., 1997; Jang et al., 1997; Kennelly et al., 1997; Zhang et al., 1992). It has also been used to evaluate the potency of various purified phytochemicals and synthetic compounds (Dinkova-Kostova and Talalay, 1999; Khachick et al., 1999; Posner et al., 1994).

Results of the present study demonstrate a high correlation between QRIP and direct paired-ion HPLC of plant extracts for quantitation of GR. Although the use of analyical chemical assays (e.g., paired-ion HPLC) to quantify GR in broccoli has proven a straightforward means of analysis, our results indicate that assessment of the Phase $2(\mathrm{QR})$ induction potential of broccoli might be an additional and useful character on which to focus in future efforts to enhance chemoprotective attributes of broccoli cultivars.

\section{Literature Cited}

Beecher, C.W.W. 1994. Cancer preventive properties of varieties of Brassica oleracea: A review. Amer. J. Clin. Nutr. 59(Suppl.):1166S1170S.

Benson, A.M., R.P. Batzinger, S.-Y.L. Ou, E. Bueding, Y.-N. Cha, and P. Talalay. 1978. Elevation of hepatic glutathione S-transferase activities and protection against mutagenic metabolites of benzo(a)pyrene by dietary antioxidants. Cancer Res. 38:4486-4495.

Benson A.M., M.J. Hunkeler and P. Talalay. 1980. Increase of $\mathrm{NAD}(\mathrm{P}) \mathrm{H}$ :quinone reductase by dietary antioxidants: Possible role in protection against carcinogenesis and toxicity. Proc. Natl. Acad. Sci. USA 77:5216-5220.

Block, G., B. Patterson, and A. Subar. 1992. Fruit, vegetables, and cancer prevention: A review of the epidemiological evidence. Nutr. Cancer 18:1-19.

Borchers, E.A. 1968. Yield, uniformity of heading and season of maturity of broccoli inbreds, hybrids and varieties. Proc. Amer. Soc. Hort. Sci. 93:352-355.

Carlson, D.G., M.E. Daxenbichler, C.H. vanEtten, W.F. Kwolek, and P.H. Williams. 1987. Glucosinolates in crucifer vegetables: Broccoli, brussels sprouts, cauliflower, collards, kale, mustard greens, and kohlrabi. J. Amer. Soc. Hort. Sci. 112:173-178.

Cook, W.P. and D.O. Ezell. 1983. Commercial broccoli production in South Carolina. Clemson Univ. Coop. Ext. Serv. Hort. Lflt. 52.

Dinkova-Kostova A. and P. Talalay. 1999. Relation of structure of curcumin analogs to their potencies as inducers of Phase 2 detoxication enzymes. Carcinogenesis 20:911-914.

Fahey, J.W., K.K. Stephenson, and P. Talalay. 1998. Glucosinolates, myrosinase, and isothiocyanates: Three reasons for eating Brassica vegetables, p. 16-22. In: T. Shibamoto, J. Terao, and T. Osawa (eds.). Functional foods for disease prevention I. Fruits, vegetables and teas. Amer. Chem. Soc. Symp. Ser. 701. Amer. Chem. Soc., Wash., D.C.

Fahey, J.W., Y. Zhang, and P. Talalay. 1997. Broccoli sprouts: An exceptionally rich source of inducers of enzymes that protect against chemical carcinogens. Proc. Natl. Acad. Sci. USA 94:10367-10372.

Farnham, M.W. 1998. Doubled haploid broccoli production using anther culture: Effect of anther source and seed set characteristics of derived lines. J. Amer. Soc. Hort. Sci. 123:73-77.

Faulkner, K., R. Mithen, and G. Williamson. 1998. Selective increase of the potential anticarcinogen 4-methylsulphinylbutyl glucosinolate in broccoli. Carcinogenesis 19:605-609.

Giamoustaris, A. and R. Mithen. 1996. Genetics of aliphatic glucosinolates. IV. Side-chain modification in Brassica oleracea. Theor. Appl. Genet. 93:1006-1010. 
Hecht S.S. 1995. Chemoprevention by isothiocyanates. J. Cell. Biochem. 22(Suppl.):195-209.

Hulbert, S.H. and T.J. Orton. 1984. Genetic and environmental effects on mean maturity date and uniformity in broccoli. J. Amer. Soc. Hort. Sci. 109:487-490.

Jang, M., L. Cai, G.O. Udeani, K.V. Slowing, C.F. Thomas, C.W. Beecher, H.H. Fong, N.R. Farnsworth, A.D. Kinghorn, R.G. Mehta, R.C. Moon, and J.M. Pezzuto. 1997. Cancer chemopreventive activity of resveratrol, a natural product derived from grapes. Science 275:218-220.

Kennelly, E.J., C. Gerhauser, and L.L. Song . 1997. Induction of quinone reductase by withanolides isolated from Physalis philadelphica (Tomatillos). J. Agr. Food Chem 45:3771-3777.

Kensler, T.W. 1997. Chemoprevention by inducers of carcinogen detoxication enzymes. Environ. Health Perspec. (Suppl.) 105:964-970.

Khachik, F., J.S. Bertram, M.-T. Huang, J.W. Fahey, and P. Talalay. 1999. Dietary carotenoids and their metabolites as potentially useful chemoprotective agents against cancer, p. 203-229. In: L. Packer, M. Hiramatsu, and T. Yoshikawa (eds.). Proc. Intl. Symp. Antioxidant Food Supplements in Human Health, Academic Press, San Diego.

Kohlmeier, L. and L. Su. 1997. Cruciferous vegetable consumption and colorectal cancer risk: Meta-analysis of the epidemiological evidence. FASEB J. 11:2141.

Kushad, M.M., A.F. Brown, A.C. Kurlich, J.A. Juvik, B.P. Klein, M.A. Wallig, and E.H. Jeffery. 1999. Variation of glucosinolates in vegetable crops of Brassica oleracea. J. Agr. Food Chem. 47:1541-1548.

Michaud, D.S., D. Spiegelman, S.K. Clinton, E.B. Rimm, W.C. Willett, and E.L. Giovannucci. 1999. Fruit and vegetable intake and incidence of bladder cancer in a male prospective cohort. J. Natl. Cancer Inst. 91:605-613.

Posner G.H., C.-G Cho, J.V. Green, Y. Zhang, and P. Talalay. 1994. Design and synthesis of bifunctional isothiocyanate analogs of sulforaphane: Correlation between structure and potency as inducers of anticarcinogenic detoxication enzymes. J. Med. Chem. 37:170-176.

Prestera, T., J.W. Fahey, W.D. Holtzclaw, C. Abeygunawardana, J.L. Kachinski, and P. Talalay. 1996. Comprehensive chromatographic and spectroscopic methods for the separation and identification of intact glucosinolates. Anal. Biochem. 239:168-179.

Prestera T., P. Talalay, J. Alam, Y.I. Ahn, P.J. Lee, and A.M.K. Choi. 1995. Parallel induction of heme oxygenase-1 and chemoprotective phase 2 enzymes by electrophiles and antioxidants: Regulation by upstream antioxidant-responsive elements (ARE). Mol. Medicine $1: 827-837$.
Prestera T., Y. Zhang, S.R. Spencer, C. Wilczak, and P. Talalay. 1993. The electrophile counterattack response: Protection against neoplasia and toxicity. Adv. Enzyme Regulat. 33:281-296.

Prochaska, H.J., A.B. Santamaria, and P. Talalay. 1992. Rapid detection of inducers of enzymes that protect against carcinogens. Proc. Natl. Acad. Sci. USA 89:2394-2398.

Rosa E.A.S., R.K. Heaney, G.R. Fenwick, and C.A.M. Portas. 1997. Glucosinolates in crop plants. Hort. Rev. 19:99-215.

Shapiro T.A., J.W. Fahey, K.L. Wade, K.K. Stephenson, and P. Talalay. 1998. Human metabolism and excretion of cancer chemoprotective glucosinolates and isothiocyanates of cruciferous vegetables. Cancer Epidemiol. Biomark. Prev. 7:1091-1100.

Shelp, B.J., L. Liu, and D. McLellan. 1993. Glucosinolate composition of broccoli (Brassica oleracea var. italica) grown under various boron treatments at three Ontario sites. Can. J. Plant Sci. 73:885-888.

Shikita, M., J.W. Fahey, T.R. Golden, W.D. Holtzclaw, and P. Talalay. 1999. An unusual case of "uncompetitive activation" by ascorbic acid: Purification and kinetic properties of a myrosinase from Raphanus sativus seedlings. Biochem. J. 341:725-732.

Steinmetz, K.A. and J.D. Potter. 1996. Vegetables, fruit and cancer prevention: A review. J. Amer. Dietetic Assn. 96:1027-1039.

Talalay, P. 1992. The role of enzyme induction in protection against carcinogenesis, p. 469-478. In: L.W. Wattenberg, M. Lipkin, C.W. Boone, and G.J. Kelloff (eds.). Cancer chemoprevention. CRC Press, Boca Raton, Fla.

Talalay, P., J.W. Fahey, W.D. Holtzclaw, T. Prestera, and Y. Zhang. 1995. Chemoprotection against cancer by Phase 2 enzyme induction. Toxicol. Lett. 82/83:173-179.

Verhoeven, D.T.H., H. Verhagen, R.A. Goldbohm, P.A. van den Brandt, and G. van Poppel. 1997. A review of mechanisms underlying anticarcinogenicity by Brassica vegetables. Chem. Biol. Interac. 103:79-129.

Zhang, Y., T.W. Kensler, C.G. Cho, G.H. Posner, and P. Talalay. 1994 Anticarcinogenic activities of sulforaphane and structurally related synthetic norbornyl isothiocyanates. Proc. Natl. Acad. Sci. USA 91:3147-3150.

Zhang, Y. and P. Talalay. 1994. Anticarcinogenic activities of organic isothiocyanates: Chemistry and mechanisms. Cancer Res. 54(Suppl.):1976s-1981s.

Zhang, Y., P. Talalay, C.G. Cho, and G.H. Posner. 1992. A major inducer of anticarcinogenic protective enzymes from broccoli: Isolation and elucidation of structure. Proc. Natl. Acad. Sci. USA 89:2399-2403. 